\title{
1 The sources of variation for individual prey-to-predator size ratios
}

2 Jorge F. Henriques ${ }^{1,2 *}$, Mariángeles Lacava ${ }^{3}$, Celeste Guzman², Maria Pilar Gavín-

3 Centol $^{2}$, Dolores Ruiz-Lupión ${ }^{2}$, Eva De Mas2, Sara Magalhães ${ }^{1 * *}$, Jordi Moya-Laraño ${ }^{2 * *}$

4

$5{ }^{1}$ cE3c - Centre for Ecology, Evolution and Environmental Changes, Faculdade de Ciências,

6 Universidade de Lisboa, Lisboa, Portugal

$7 \quad{ }^{2}$ Functional and Evolutionary Ecology, Estación Experimental de Zonas Áridas, CSIC, Carretera

8 de Sacramento s/n, 04120-La Cañada De San Urbano, Almeria, Spain

$9 \quad{ }^{3}$ Centro Universitario de Rivera, Universidad de la República, Ituzaingó, 667 Rivera, Uruguay

$10 * *$ co-last authors

$11 *$ Corresponding author: Jorge F. Henriques

12 E-mail: henriquesjfp@gmail.com

13 Centre for Ecology, Evolution and Environmental Changes, Faculdade de Ciências, Universidade

14 de Lisboa, Edifício C2, 5o Piso, Sala 2.5.46 Campo Grande

15 1749-016 Lisboa, Portugal

$16 \quad$ Phone. +351217500577

$17 \quad$ Fax. +351217500028

18

19 Running title: Individual variation in prey-to-predator size ratio

Word count: 5669

22 Citation: Henriques J. F., Lacava M., Guzman C., Gavín-Centol M. P., Ruiz-Lupión D., De

23 Mas E., Magalhães S.* and Moya-Laraño J. *(* co-last) (2021). The sources of variation

24 for individual prey-to-predator size ratios. Heredity 126:684-694.

25 https://doi.org/10.1038/s41437-020-00395-5 
27 The relative body size at which predators are willing to attack prey, a key trait for predator-prey interactions, is usually considered invariant. However, this ratio can vary widely among individuals or populations. Identifying the range and origin of such variation is key to understanding the strength and constraints on selection in both predators and prey. Still, these sources of variation remain largely unknown. We filled this gap by measuring the genetic, maternal and environmental variation of the maximum prey-to-predator size ratio (PPSRmax) in juveniles of the wolf spider Lycosa fasciiventris using a paternal half-sib split brood design, in which each male was paired with two different females and the offspring reared in two different food environments: poor and rich. Each juvenile spider was then sequentially offered crickets of decreasing size and the maximum prey size killed was determined. We also measured body size and body condition of spiders upon emergence and just before the trial. We found low, but significant heritability $(h 2=0.069)$ and dominance and common environmental variance $(d 2+4 c 2=0.056)$. PPSRmax was also partially explained by body condition (during trial) but there was no effect of the rearing food changes in this trait in the short and long terms.

Keywords: Predator-prey interactions, heritability, additive variance, dominance 
51 Different sources of phenotypic variation have different implications for ecology and evolution. Indeed, responses to selection mostly rely on the additive genetic variation, but other sources of variation may affect some of the characteristics of this response. Additionally, from an ecological perspective, all sources of trait variation may in principle impact ecosystem functioning. Changes in the latter will in turn set the stage for new selection pressures to operate on individual traits (Bolnick et al. 2003; Violle et al. 2012; Hart et al. 2016; Costa-Pereira et al. 2018). This is particularly important in traits that evolve at fast rates. Indeed, different sources of trait variation may indirectly affect evolutionary responses by inducing environmental changes that subsequently act as new selective pressures. This is the case when phenotypic variation affects ecological interactions, such as predation (e.g. Moya-Laraño 2011; Bolnick et al. 2011; Schreiber et al. 2011). Understanding the potential impact of phenotypic variation on predator-prey interactions and its evolutionary potential thus requires identifying the origin of such variation (Bolnick et al. 2011).

Theory predicts that the effect of intraspecific variation upon the outcome of ecological interactions depends on the relative strength of environmental vs genetic variation (Schreiber et al. 2011; Moya-Laraño et al. 2014; Cortez, 2018; Maynard et al. 2019). For example, depending on the type of interaction, systems where the phenotypic variance of traits is largely determined by genetic variance tend to be more (e.g., competition - Maynard et al. 2019) or less (e.g., apparent competition Schreiber et al. 2011) stable than those where trait variation depends on environmental conditions. Also, since genetic variability enhances evolutionary responses, genetic diversity (number of genotypes) in prey can lead to the stabilization 
of predator-prey dynamics via the evolution of resistance to predation (Yoshida et al. 2003).

Maternal effects can also contribute to stabilizing predator-prey interactions, as shown both theoretically (Benton et al. 2001; Inchausti and Ginzburg 2009) and empirically (Gustafsson et al. 2005; Sheriff et al. 2010). Maternal effects can add up to $50 \%$ of the total phenotypic variance of traits (Moore et al. 2019) and these effects can strongly impact the expression of traits involved in predator-prey interactions (LaMontagne and McCauley 2001; Walsh et al. 2016). Maternally driven phenotypic changes may also impact adaptive responses, as they can be a pervasive source of trait variation in the absence of strong additive genetic effects (Wolf and Wade 2016) and can contribute to evolution, especially in variable environments (Dey et al. 2016). Other non-additive genetic effects, such as dominance and epistasis can potentially affect ecological and evolutionary dynamics as well. Indeed, the contribution of dominance to fitness related traits can be relatively high (Mousseau and Roff 1987; Crnokrak and Roff 1995; Wang et al. 1998; Wolak and Keller 2014; Sztepanacz and Blows 2015; summarized in Caballero 2020; but see Class and Brommer 2020). Dominance can stabilize the dynamics of predator-prey interactions (Stewart 1971). Although the contribution of epistasis should not be ruled out (Hansen 2013), it is difficult to quantify in natural populations (Carlborg and Haley 2004) and laboratory crossing designs are not amenable for species with long generation times (Lynch and Walsh 1998).

Genetic correlations among traits also have the potential to foster or constrain evolutionary (Cheverud 1996; Roff 1997) as well as ecological responses. For instance, simulations show that depending on temperature genetic correlations can 
differentially affect predator-prey interactions (Moya-Laraño et al. 2012). Maternal effects may also impact multiple traits simultaneously, acting as a source of covariation among offspring traits, thus generating maternal correlations, through non-genetic factors such as hormones (McGlothlin and Ketterson 2008).

Body size is one of the most fundamental functional traits of an organism (Brown et al. 2004). It determines trophic position, as larger predators may be able to feed on relatively smaller prey (Woodward and Hildrew 2002; Woodward et al. 2010). Therefore, it is a fundamental trait to determine the strength of interactions in food webs, and thus their stability (Jonsson and Ebenman 1998; Emmerson and Raffaelli 2004; Rooney et al. 2006; Otto et al. 2007; Schneider et al. 2016). Variation in body size is determined by several sources, including genetic, maternal, dominance and environmental variation (Gebhardt-Henrich and Van Noordwijk 1991; Mousseau and Fox 1998; De Jong and Imasheva 2000). However, due to the long-standing practice in community ecology of collapsing species to their mean values (Tilman et al. 2014), the relative size of interacting predators and prey, captured by the predator-prey size ratio, is traditionally considered to be invariant for a given predator-prey interaction (Brose et al. 2006, 2008; Laigle et al. 2018; Cuthbert et al. 2020). However, there is ample evidence for within-species variation in size with large consequences for predator-prey interactions and community dynamics (De Roos et al. 2003; Magalhães et al. 2005; Nakazawa et al. 2011). Therefore, ignoring this variability may lead to erroneous estimations of the scaling relationship between predators and prey.

Here, we investigate the sources of intraspecific variation in prey-to-predator size ratio of the soil predator Lycosa fasciiventris (Dufour 1835), a non-burrowing wolf spider inhabiting the Iberian Peninsula. Spiders of this genus are generalist predators, 
122 feeding on an array of mid to large size arthropods including conspecifics (Moya-

123 Laraño et al. 2002; Gavín-Centol et al. 2017). Specifically, we assess the role of

124 additive, maternal and environmental effects in determining the prey-to-predator size

125 ratio of spiders feeding on crickets, a common prey of wolf spiders and abundant in

126 the habitat of this species. Identifying the relative contribution of environmental,

127 maternal and genetic components affecting variation in PPSR will shed light into its

128 evolutionary potential and provide a deeper understanding of its potential to

129 modulate community structure and ultimately ecosystem functioning.

\section{Material and Methods}

\section{Spider collection}

Individuals of Lycosa fasciiventris were collected from June $23^{\text {rd }}$ to July $27^{\text {th }} 2015$ in

134 four different localities within the Almeria province (South-East Spain), in dry temporal washes ("ramblas"): 1) around Paraje las Palmerillas, Estación Experimental de

Cajamar $\left(36.7917^{\circ} \mathrm{N}, 2.6891^{\circ} \mathrm{O}\right)$; 2) near Boca de los Frailes village $\left(36.8036^{\circ} \mathrm{N}\right.$,

$\left.2.1386^{\circ} \mathrm{O}\right)$; 3) near Carboneras village $\left(36.9667^{\circ} \mathrm{N}, 2.1019^{\circ} \mathrm{O}\right)$ and 4) near Almanzora river $\left(37.3414^{\circ} \mathrm{N}, 2.0078^{\circ} \mathrm{O}\right)$. Individuals were then kept separately in the laboratory in a container $(22 \times 18 \times 18 \mathrm{~cm})$ with the bottom filled with $2-3 \mathrm{~cm}$ of soil collected from the sampling sites. Two wooden blocks $(10 \times 8 \times 1 \mathrm{~cm}$ and $3 \times 5 \times 1 \mathrm{~cm})$ were added to each tank to provide shelter. Only sub-adult virgin females were used to form the laboratory population. All individuals (adult and sub-adult males, and sub-adult

143 females) were fed once a week with size-matched crickets (Gryllus assimilis; Fabricius 1775) purchased from a pet supply online store Exofauna, Spain (available in: 
https://exofauna.com). Spiders had access to water ad libitum through a $40 \mathrm{ml}$ vial filled with water and covered with cotton. Tanks were placed in a climate chamber with simulated outdoor climatic conditions (day and night temperature cycles and photoperiod with light fluorescent tubes of $54 \mathrm{~W}$, mimicking natural sunshine, and a relative humidity from 50 to $65 \%$ ). Climatic conditions were adjusted to the preceding weekly average conditions in the Almeria province, with day-night temperature and light oscillations (temperature: $18.7-34.3^{\circ} \mathrm{C}$; light-dark photoperiod: 17:7-16:8 hours).

\section{Breeding design}

To assess genetic, maternal and environmental variation in individual prey-to-predator size ratio (PPSR), we performed a paternal half-sib split-brood design (Roff 1997; Lynch and Walsh 1998), in which 52 males (sires) were each mated with two virgin females (dams). Each week, offspring were provided with fruit flies (Drosophila melanogaster; Meigen 1830) originated from cultures produced in the laboratory. Flies were fed with a nitrogen rich medium supplemented with high quality dogfood, which highly improves spider survival (Jensen et al. 2011). Maternal families were constituted by 12 offspring, split into two food availability treatments, varying in the number of flies provided. Thus, 3 out of 12 offspring from each maternal family were assigned to the rich environment, being given $3 \times$ the amount of food provided in the poor (or standard) environment. Initially, a single fly was offered to the spiders in the poor treatment and 3 flies in the richer treatment. This quantity was adjusted to 3 and 9 when individuals were approximately 6 months old due to higher food demand at that stage. 

fasciiventris, remain with it for a period of a few weeks (Parellada 1998). Due to logistic reasons, all spiderlings were removed from the female back within one week, that is approximately $42 \pm 8$ (mean \pm SD) days after they hatched (age at isolation). To estimate and control for post-hatching common environmental effects occurring on the female back, the age at isolation was included in all models. This variable was never significant (data not shown). Spiderlings were carefully collected from the female back with the help of a paintbrush. We took 12 spiderlings from each female and placed them separately in cylindrical containers $(5 \mathrm{~cm}$ height and $6 \mathrm{~cm}$ diameter).

Each container had the bottom covered with filter paper, providing a substrate for both locomotion and absorption of excreta, inside the growth chamber. Filter papers were checked weekly and replaced if necessary. A plastic tip was inserted at the bottom of the container, filled with cotton connected to a reservoir, providing water ad libitum to spiders by capillarity (Moskalik and Uetz 2011). The 1248 spiderling containers were then randomly arranged within the growth chamber to ensure that individuals belonging to the same family were spatially interspersed. This allowed mitigating possible common environmental effects after spiderling isolation from their mothers.

\section{Morphometry}

Body components were divided between structural body size (carapace width; Hagstrum 1971) and body condition (residuals of abdomen width on carapace width; (Jakob et al. 1996). Body condition reflects energy and nutrient storage independently on the size of the spider and thus reflects hunger level (Moya-Laraño et al. 2008). 
Structural body size may reflect the strength to subdue prey (e.g., Moya-Laraño et al. 2002). Both carapace and abdomen width were measured at their widest point. Body size and body condition were measured in two instances: after individuals were taken from their mothers and isolated, and immediately before the trials for acceptance. Morphometric measurements were taken to the nearest $0.1 \mathrm{~mm}$ with a dissection microscope (Leica MZ125). While structural body size measured at the time of trial was needed to calculate prey-to-predator size ratio, body condition at the time of the trial was used to control for the hunger state of each spiderling (i.e. its motivational state). These traits were also measured early in life and used to calculate genetic and maternal correlations, to test how maternal investment in both offspring body size and condition could affect behavioural patterns of the spiders later in life.

\section{Prey acceptance}

This experiment aimed to measure the maximum relative size of a prey cricket (Gryllus assimilis) that a spider accepted, considering a range of cricket lengths (in $\mathrm{mm}$ ) decreasing from $5 \times$ to $1 \times$ (in units of 1 ) the carapace width of the spider. For that, we placed them in experimental arenas where each spider was offered crickets in a decreasing order of relative size until it subdued and killed a cricket. The response variable, prey-to-predator size ratio (PPSR) is the ratio at which the spider attacks and kills the cricket. This measure corresponds to the maximum PPSR (PPSR $\max$ ) at which predators kill their prey and the larger the relative size of the prey killed, the higher the PPSR. Spiders were measured in blocks of $17 \pm 5$ (mean \pm SD) individuals. Each block was defined as the experimental batch of individuals assessed in each day. 

bimaculatus, is highly abundant in the collection area (Moya-laraño personal observation). As it was not feasible to collect G. bimaculatus in numbers enough to carry out this study, we used G. assimilis individuals from an established laboratory population. Note that this approach allowed testing the response of spiders that were naive to this prey, as all spiders had been fed with Drosophila to that point. Thus, this approach minimized environmental variation due to potential effects of previous experiences with cricket prey.

In the trial, we used crickets with a length that differed from the target PPSR $(5 x, 4 \times, 3 x, 2 x$ or $1 \times$ of the width of the spider carapace) by less than 0.2 units. Crickets were weighted, and their length determined from a calibration curve, previously generated with the weight and length of 40 crickets: $L=3.22+0.32 \log (M) ; R^{2}=0.99 ; p$ XP26). None of the crickets were used in more than one trial.

To standardize hunger levels across individuals, spiders were left to starve for seven days before being tested, similarly to other studies (Persons and Rypstra 2000). covariate (see below). A single spider and one cricket were placed inside the arena (7.5 
238 Then, both vials were gently lifted simultaneously, and crickets and spiders were

239 allowed to interact for 6 minutes. If the cricket was not captured and subdued, the

240 spider was enclosed in the vial and the cricket was removed. Spiders were then left to

241 recover in the vial for 30 minutes until a new cricket from the next immediately lower

242 size was presented (lower PPSR). Trials ended as soon as the spider attacked and killed

243 a cricket or if the spider did not catch the smallest $(1 \times)$ cricket.

\section{Estimation of variance components and statistical analysis}

The paternal half-sib breeding design allows partitioning the total phenotypic variance

247

$\left(V_{P}\right)$ into the following sources of variation:

$$
V_{p}=V_{s}+V_{d}+V_{w}
$$

where $V_{s}$ is the variance among sires, $V_{d}$ the variance among dams within sires and $V_{w}$ the variance within full-sib families. The genetic/environmental causal components of the sources contributing to phenotypic variation $\left(V_{P}\right)$ are then (Lynch and Walsh 1998):

$$
V_{s}=\frac{V_{A}}{4}
$$

$$
V_{d}=\frac{V_{A}}{4}+\frac{V_{D}}{4}+V_{E C}
$$

where $V_{A}$ is the additive genetic variance, $V_{D}$ is the dominance genetic variance, $V_{E C}$ is the component of variance attributed to common environmental (maternal) effects, and $V_{E s}$ is the remaining environmental variation. The dam variance component includes, in addition to additive effects, both dominance effects and common 
environmental (maternal) effects. The potential for post-natal common environmental effects to severely inflate the estimated maternal variance $\left(V_{E c}\right)$ was reduced by

261 isolating offspring from their mothers as soon as possible after hatching, referred to above (see "breeding design" section).

Epistatic variance is implicitly included on the residual variance component, i.e. the variance within full-sib families $\left(V_{w}\right)$, as its estimation requires much more complex, cross-classified designs (Pooni et al. 1978; Lynch and Walsh 1998). These designs are unfeasible for sexually cannibalistic spiders such as L. fasciiventris (GavínCentol et al. 2017), because they require crossing males with several females and vice versa.

The estimation of variance components was performed using univariate and multivariate mixed models in the MCMCgImm package (Hadfield 2010) in R ( $\mathrm{R} 3.4 .3$ development core team 2018). In all models, we fitted body condition (at the beginning of the trial), food availability (spider in poor (1-3 flies) or in rich (3-9 flies) environment) and age as covariates. We did not include body size at the trial as a fixed factor as it is in the denominator of PPSR. Accounting for it in our models would thus result in assessing the sources of variation for prey size, not those for the relative size differences between predators and prey. Sire (the father identity), dam (the mother identity) and block (trials performed at different times) were included as random effects. All traits were standardized to unit variance and zero centred prior to analyses. We assessed the significance of variance components of PPSR $\mathrm{max}_{\max }$ by comparing deviance information criterion (DIC) values of a total of 4 plausible models, which included sire $\left(V_{s}\right)$ and/or dam $\left(V_{d}\right)$ variance components and a null model excluding both random factors. The null model included fixed effects (age, food treatment and 
body condition), and variance was partitioned only in block $\left(V_{B}\right)$ and residual $\left(V_{R}\right)$ random effects by fitting these as random terms. We then fitted a model by adding the sire variance component $\left(V_{s}\right)$ to the null model, another adding solely the dam variance component $\left(V_{d}\right)$, and a last model with both random variance components $\left(V_{s}+V_{d}\right)$.

Phenotypic variance in the most complete model comprised all the random variance components $\left(V_{P}=V_{s}+V_{d}+V_{B}+V_{R}\right)$. Models that showed a difference between DIC values $(\Delta D I C)>2$ were considered statistically different (Burnham et al. 2011).

Priors used in this analysis were generated by partitioning the phenotypic variance evenly among each random term (Wilson et al. 2010) and given a low degree of belief $(n u=0.2)$. All models were run for 200000 interactions, a burn-in of 5000 and a thinning interval of 100 .

Narrow sense heritability $\left(h^{2}\right)$ was estimated from the complete model as the proportion of additive genetic variance $\left(V_{A}=4 V_{s}\right)$ to the total phenotypic variance $\left(h^{2}=\right.$ $\left.4 V_{s} / V_{P}\right)$. Broad sense heritability $\left(H^{2}\right)$ was estimated as the proportion of 4 times the dam variance (eq. 3) to the total phenotypic variance $\left(4 V_{d} / V_{P}\right)$ and thus, includes additive $\left(h^{2}=V_{A} / V_{P}\right)$ and dominance effects $\left(d^{2}=V_{D} / V_{P}\right)$. As $V_{d}$ also includes common environmental (maternal) effects $\left(c^{2}=V_{E c} / V_{P}\right)$, the estimate of $H^{2}$ is an upper limit of its true value.

Multivariate generalized linear mixed models were used to estimate genetic and maternal correlations between PPSR $\max$ and body size and body condition at isolation. We considered these morphometric measures at isolation because we aimed to (a) test if there is a relation between early life traits and PPSR $\max$ and (b) identify the source of such covariation. We did not test covariance between body size at the time of the trial and PPSR $\max$ because the former is included in the denominator of the 
latter. Also, the covariance between PPSR $\max$ and body condition at the time of the trial

308 was not tested. Instead, the latter trait was fit as fixed effect, as variation in this trait is expected to be largely explained by the rearing environment (i.e. the food availability treatment) and is thus a good surrogate trait to control for hunger state.

Genetic correlations $\left(r_{A}\right)$ were calculated using the $\mathbf{G}$ matrix of covariance (Lynch and Walsh 1998) following the equation:

$$
r_{A}=\frac{\operatorname{cov}_{A(x y)}}{\sqrt{\left(\operatorname{var}_{A(x)}\right)\left(\operatorname{var}_{A(Y)}\right)}}
$$

where $\operatorname{COV}_{A(x y)}$ is the additive genetic covariance between two characters $X$ and $Y$, and $\operatorname{var}_{A(x)}$ and $\operatorname{var}_{A(Y)}$ are the additive genetic variance of $X$ and $Y$, respectively. Maternal correlations $\left(r_{M}\right)$ were calculated similarly but instead of variance and covariances for additive genetic effects, the expression was modified by using maternal variances $\left(\operatorname{var}_{M(x)}\right.$ and $\left.\operatorname{var}_{M(y)}\right)$ and covariances $\left(\operatorname{COV}_{M(x y)}\right)$. Priors were $2 \times 2$ diagonal matrices where the diagonal corresponded to the variance for each trait and the off-diagonal to zero covariance between traits.

A sensitivity analysis was run for all univariate and multivariate models by testing several nu parameters $(0.2-2.2)$ and revealed no substantial difference in the estimates obtained among the models tested. Moreover, we also tested for priors with varying proportion of the raw phenotypic variance attributed to the residual variances (0.025 and 0.95) (Wilson et al. 2010), leaving the remaining to be shared equally between the dam and sire components. Only the most robust results were considered, i.e., the ones which did not change substantially depending on the nu parameter or the prior variances. We evaluated model convergence by visual inspection of the time series plots of the model parameters and also ensured that autocorrelation values 
were less than 0.05 for all parameters included to grant independence of samples in the posterior distribution (Wilson et al. 2010). We also ran the models more than once to test that different chains (replicates) closely replicated our results (not shown). Posterior credible intervals $(\mathrm{Cl})$ for the estimates of narrow and broad-sense

334 heritabilities, and genetic and maternal correlations were calculated from the posterior distributions using the highest-posterior-density function (HPD interval, package MCMCgImm; Hadfield 2010). Covariances were supported when 95\% credible intervals excluded zero and when the model with sire and/or dam random effects had lower DIC values than null models. Because variances are bounded above zero, support of variances estimates was assessed by comparing the DIC values between fitted models.

\section{Results}

Individual body condition, measured before the trial, had a significant effect on $\mathrm{PPSR}_{\text {max }}$, as individuals with better condition tended to feed on larger prey (Table 1). Age and food treatment did not significantly affect PPSR $\max$ (Table 1). In addition, the food treatment had a significant effect on body size and body condition measured

347 during the behavioural trials, where individuals in the richer food treatment had 1.32x larger body sizes (Fig. S1) and 1.14x superior body condition (Fig. S2). Moreover, 349 although accepted prey size covaried positively with spider body size, we found a very wide range of absolute prey sizes accepted for a given spider body size. Also, across

351 spider body sizes, no single optimal (i.e., more frequently hunted) prey size was found 352 (Fig. S3). 
heritability value for PPSR $\max$ of $h^{2}=0.069[\mathrm{Cl}: 0.022-0.230]$. This value is low, but the model converged to a bell-shaped posterior distribution from which a global maximum (mode) could be obtained (Fig. S4). Although the best fitted model, as observed by DIC comparison, included only the dam variance component $\left(V_{d}\right)$, the complete half-sib design model (including $V_{s}+V_{d}$ ) was also different from the null model (Table 2). From 0.343], which was nearly twice as large as the $h^{2}$ estimate. body size at isolation and PPSR $\max \left(r_{M}=-0.418\right.$; [Cl: $\left.-0.725 ;-0.096\right]$; Fig. 1$)$, meaning that individuals provisioned by their mothers with a smaller size are more prone to feed on relatively larger prey in later developmental stages. No maternal correlation between body condition at isolation and PPSR $\max$ was found $\left(r_{M}=0.107\right.$; $[\mathrm{Cl}:-0.261$, 0.564]; Fig. 1). Also, we did not find any significant genetic correlation between $\mathrm{PPSR}_{\max }$ and body size or between PPSR $\max$ and body condition at isolation $\left(r_{A}=-0.129\right.$ [Cl: $-0.498 ; 0.413])$ and $r_{A}=0.089$ [Cl: $\left.-0.417 ; 0.462\right]$, respectively; Fig. 1).

\section{Discussion}

In this study, we found that additive and non-additive genetic plus maternal effects contributed to variation in prey-to-predator size ratio in the wolf spider Lycosa 373 fasciiventris. attacked and subdued relatively larger prey (higher PPSR $\max$ ). Moreover, we show that 
376 individuals from maternal families giving birth to larger offspring tended to feed on

377 smaller prey ca. 9 months ahead in their ontogeny.

378 Relative body size differences between predators and prey are often measured 379 through predator-prey body mass ratios (PPMR). However, several studies also use 380 structural body size differences between predators and prey, particularly in systems 381 similar to ours (García et al. 2018; Grinsted et al. 2020). Indeed, in spiders, body condition accounts for a large proportion of body mass in the form of storage in the abdomen (e.g., Moya-Laraño et al. 2008). Thus, structural body size differences provide better estimates of the probability that spiders subdue the prey. Note, however, that differences among individuals in PPSR $\max$ can also be related to differences in risk taking decisions or in costs such as handling time (Woodward and Warren 2007).

Some studies have measured the preference of predators for prey of different sizes (Shultz et al. 2004; Matlock 2005). Preference is clearly an important trait defining dietary breadths (Poore and Hill 2006) and it is therefore ecologically relevant (Singer 1986; Jiang and Morin 2005; Boll and Leal-Zanchet 2016). However, size is a continuous variable, hence choice experiments (which generally use two prey items only) will necessarily leave out much of the variation in prey size. Additionally, prey acceptance may be more ecologically realistic than preference, as predators often encounter prey sequentially (Nentwig and Wissel 1986). Therefore, maximum prey size acceptance is probably a relevant trait for this predator, as for many others. For example, a previous study showed that differences in foraging efficiency of two instars of the dragonfly Aeshna juncea were more clearly perceived when this trait was measured in trials involving the larger prey size (Hirvonen and Ranta 1996). 
directly collected from their environment like gut contents (Agashe and Bolnick 2010;

402 Costa-Pereira et al. 2018). These measures correspond to the actual composition of prey eaten, but they can be strongly affected by the relative prevalence of different prey types in the environment (Costa-Pereira et al. 2018). It has been argued that it is this context-dependence that accounts for the discrepancy between model assumptions of a constant PPSR and data, which show variable within-species PPSR (Tsai et al. 2016). Here, we provide a measurement that is independent of the environmental context and show that variation is still present. to estimate the variance components responsible for individual variation in this trait. Indeed, we show that such variation is due to additive and dominance or maternal effects. Therefore, such variation is not simply a by-product of environmental conditions and needs to be accounted for in studies addressing the ecology and evolution of body size in predators (Nakazawa 2017). In our design, we cannot disentangle the relative contribution of dominance and maternal effects to the dam variance. Previous studies exploring the importance of dominance in several traits 417 have concluded that it has a proportionally higher impact on trait variation when additive genetic variance is eroded by natural selection, most commonly in fitness related traits (Crnokrak and Roff 1995; Merilä et al. 2001). Given the low values of narrow sense heritability observed here, dominance (along with maternal effects) may

421 be an important determinant of trait variation (Crnokrak and Roff 1995). Indeed, studies with laboratory populations have shown that dominance can account for as much as $38 \%$ of the total phenotypic variation (Wolak and Keller 2014). However, a 
recent study focusing on morphological and behavioural traits has shown that dominance variance is negligible (or difficult to detect) in wild passerine populations

426 (Class and Brommer 2020). In this same study, based on simulation data, it was 427 observed that neglecting dominance variance can indeed inflate the estimates of 428 additive genetic variance and heritability. However, inflation of the estimates can be kept relatively small if maternal variance is also controlled for. Nonetheless, the data comes from a particular case-study and thus one single value of environmental variance, which can greatly differ across species, populations, and traits. Remarkably, the results of these same simulations found that dominance and environmental effects can be strongly confounded in animal models, which suggests that there is still plenty of room for, at least, moderate dominance effects to operate in wild populations. Future work should implement other breeding designs, such as the production of maternal half-sib families to properly estimate dominance in this and other systems. Additionally, the traits we are considering are probably polygenic, hence there is room for epistasis to significantly contribute to trait variance. However, the complex designs needed to estimate this variance component are beyond the capacity of the current study.

Variation in PPSR max , measured ca. 9 months after spiderlings were separated from their mothers, was still affected by dominance or maternal variance. This suggests that either dominance or long-lasting maternal mechanisms, such as hormones and/or other maternally inherited factors (Groothuis and Schwabl 2008), contribute to variation in this trait. Indeed, some studies show that maternal effects can still be found later in life, although they generally wane throughout the ontogeny 
Réale 2006). We found that the relative contribution of maternal plus dominance variance $\left(d^{2}+4 c^{2}\right)$ was small $(0.056)$ and of similar magnitude than that of the 450 heritability (0.069). Overall, the maximum value of the broad sense heritability that we estimated was 0.125 . This implies that evolutionary responses of this trait may be rather small, suggesting that PPSR $\max$ has been under strong selection in the past. A very high environmental variance in PPSR $_{\max }$ can still impact predator-prey dynamics, due to predator selection pressure upon prey that differ in size. In addition, part of this environmental variation may be explained by other variables, such as individual state. Indeed, here we found that individuals in better body condition tended to display a

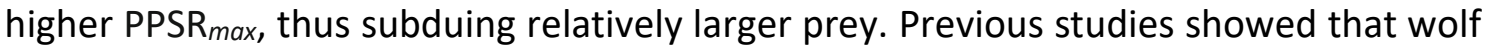
spiders with more energy reserves tend to spend less time and effort hunting (e.g., Moya-Larano et al. 1998; Moya-Larano 2002), suggesting that spiders in better condition are less motivated to hunt. Our results cannot be explained by this motivational state hypothesis. Possibly, in our case, relatively heavier spiders have higher chances of subduing larger crickets, as spiders jump on top of crickets to do so. Alternatively, spiders in better condition are willing to spend more energy to subdue larger prey.

Surprisingly, the food treatment did not affect PPSR $\max$, although spiders in the 466 richer food treatment tended to be of superior body size and body condition (Fig. S1, S2). Differences in other traits underlying body condition, such as differences in assimilation efficiency, could be responsible for body condition being linked to PPSR $_{\max }$, instead of food treatment. 
472 also offspring that displayed a lower PPSR $\max$ ca. 9 months later in life. Individuals born

473 larger may be less willing to take unnecessary risks later in life, because in the wild 474 they would have enjoyed a relatively milder environment through their ontogeny. 475 These spiderlings, born slightly larger, may be less willing to attack relatively larger 476 prey later in life because while capturing larger prey is more energetically rewarding, it 477 may come with the cost of longer handling time (which includes pursuit and subduing time, ingestion time and digestion) and the possibility of injuries inflicted by the prey 479 (Griffiths 1980), as it is the case for spiders preying on crickets (Gnatzy and Otto 1996). Alternatively, this maternal correlation may represent a particular case of a "silver spoon effect", defined as an increased fitness throughout the lifetime of an organism due to being better provisioned early in life (Grafen 1988; Cockburn 1991). To disentangle between these hypotheses, we would need to measure the fitness of individuals that were born bigger and exhibit a lower PPSR $\max$ and that of smaller individuals with higher PPSR $\max$, and observe fitness differences between the two. Finally, there is the possibility that at least part of the variance explained by this correlation is due to pleiotropic dominance effects (Keightley and Kacser 1987), which we cannot distinguish from maternal correlations in our design.

Theory predicts that genetic architecture, including genetic correlations, is key to understand the impact of trait variation on coexistence (Schreiber et al. 2018; Patel et al. 2019). Moreover, genetic correlations among traits can accelerate or hinder evolutionary responses (Chevin 2013). When evolutionary processes occur within similar timeframes as ecological processes, such correlations can affect ecoevolutionary dynamics and system stability (Patel et al. 2018). Under this rationale, the maternal correlations described in this study could also affect predator-prey dynamics. 
497 individual dietary specialization, i.e. inter-individual variation in resource use (Bolnick

498 et al. 2002, 2003; Araújo et al. 2011). Specifically, the dam component of PPSR $\max$ explains some proportion of the variation in individual niche specialization (Bolnick et al. 2003). Maintenance of inter-individual diet variation allows populations to maintain stability when faced with competition and predation, but it also exerts different forms of selection on prey species (reviewed in Bolnick et al. 2003). Still, there is little evidence for how this specialization affects community dynamics (Araújo et al. 2011) and further studies including the sources of variation on individual specialization are needed.

Our results thus highlight that accounting for individual variation in PPSR may 507 help unravel the evolutionary factors shaping this trait. Such a variation can, in turn, 508 impact ecological interactions. Additionally, by diversifying prey selection, individual 509 variation in PPSR may allow for the maintenance of variation in prey sizes, as it will 510 spread the predation pressure across prey differing in body size (Ye et al. 2013).

511 Therefore, individual variation in PPSR stands at the intersection between the 512 ecological and evolutionary impacts of predator-prey interactions, playing an 513 important role as a key predictor of food web persistence and its associated ecosystem processes, and less so of evolutionary trajectories, at least as a source of direct responses. 


\section{Acknowledgments}

519 We thank D. Mayntz and K. Jensen for providing the recipes for the media used to 520 culturing nitrogen-enriched Drosophila. This study was supported by a PhD grant

521 (PD/BD/106059/2015) attributed to Jorge Henriques by the Portuguese Science and 522 Technology foundation (FCT), by the grant P12-RMN-1521 from the Andalusian 523 government and by the grant CGL2015-66192-R from the Spanish Ministry of Economy 524 and Competitiveness, both partially funded by the European Regional Development 525 Found, both attributed to Jordi Moya-Laraño and to the FPU scholarship 526 (FPU13/04933) from the Spanish Ministerio de Educacion, Cultura y Deporte to 527 Dolores Ruiz-Lupión.

528

529 Competing interests

530 The authors declare they have no conflict of interests.

\section{Data Availability}




\section{References}

538

539

540

541

542

Agashe D, Bolnick DI (2010) Intraspecific genetic variation and competition interact to influence niche expansion. Proc R Soc B Biol Sci 277:2915-2924.

Araújo MS, Bolnick DI, Layman CA (2011) The ecological causes of individual specialisation. Ecol Lett 14:948-958.

Benton TG, Ranta E, Kaitala V, Beckerman AP (2001) Maternal effects and the stability of population dynamics in noisy environments. J Anim Ecol 70:590-599.

Bernardo J (1996) Maternal Effects in Animal Ecology. Am Zool 36:83-105.

Boll PK, Leal-Zanchet AM (2016) Preference for different prey allows the coexistence of several land planarians in areas of the Atlantic Forest. Zoology 119:162-168.

Bolnick DI, Amarasekare P, Araújo MS, Bürger R, Levine JM, Novak M, et al. (2011) Why intraspecific trait variation matters in community ecology. Trends Ecol Evol 26:183-192.

Bolnick DI, Svanbäck R, Fordyce JA, Yang LH, Davis JM, Hulsey CD, et al. (2003) The ecology of individuals: Incidence and implications of individual specialization. Am Nat 161:1-28.

Bolnick DI, Yang LH, Fordyce JA, Davis JM, Svanbäck R (2002) Measuring individuallevel resource specialization. Ecology 83:2936-2941.

Brose U, Ehnes RB, Rall BC, Vucic-Pestic O, Berlow EL, Scheu S (2008) Foraging theory predicts predator-prey energy fluxes. J Anim Ecol 77:1072-1078.

Brose U, Jonsson T, Berlow EL, Warren P, Banasek-Richter C, Bersier LF, et al. (2006) Consumer-resource body-size relationships in natural food webs. Ecology $87: 2411-2417$ 
Brown JH, Gillooly JF, Allen AP, Savage VM, West GB (2004) Toward a metabolic theory of ecology. Ecology 85:1771-1789.

Burnham KP, Anderson DR, Huyvaert KP (2011) AIC model selection and multimodel inference in behavioral ecology: Some background, observations, and comparisons. Behav Ecol Sociobiol 65:23-35.

Caballero A (2020) Quantitative Genetics. Cambridge University Press.

Carlborg Ö, Haley CS (2004) Epistasis: Too often neglected in complex trait studies? Nat Rev Genet 5:618-625.

Cheverud JM (1996) Development integration and evolution of pleiotropy. Am Zool $36: 44-50$.

Chevin LM (2013) Genetic constraints on adaptation to a changing environment. Evolution 67:708-721.

Class B, Brommer JE (2020) Can dominance genetic variance be ignored in evolutionary quantitative genetic analyses of wild populations? Evolution 74:1540-1550.

Cockburn A (1991) An introduction to evolutionary ecology. Blackwell Scientific Oxford. Cortez MH (2018) Genetic variation determines which feedbacks drive and alter predator-prey eco-evolutionary cycles. Ecol Monogr 88:353-371.

Costa-Pereira R, Araújo MS, Olivier R da S, Souza FL, Rudolf VHW (2018) Prey Limitation Drives Variation in Allometric Scaling of Predator-Prey Interactions. Am Nat 192:139-149.

Crnokrak P, Roff DA (1995) Dominance variance: Associations with selection and fitness. Heredity 75:530-540.

Cuthbert RN, Wasserman RJ, Dalu T, Kaiser H, Weyl OLF, Dick JTA, et al. (2020) Influence of intra- and interspecific variation in predator-prey body size ratios on 

trophic interaction strengths. Ecol Evol 10:5946-5962.

585

586

587

588

589

590

591

592

594

595

596

597

598

599

600

601

602

603

604

605

606

607

Dey S, Proulx SR, Teotónio H (2016) Adaptation to Temporally Fluctuating Environments by the Evolution of Maternal Effects. PLOS Biol 14(2):e1002388.

Emmerson MC, Raffaelli D (2004) Predator-prey body size, interaction strength and the stability of a real food web. J Anim Ecol 73:399-409.

García LF, Viera C, Pekár S (2018) Comparison of the capture efficiency, prey processing, and nutrient extraction in a generalist and a specialist spider predator. Sci Nat 105:30.

Gavín-Centol MP, Kralj-Fišer S, De Mas E, Ruiz-Lupión D, Moya-Laraño J (2017) Feeding regime, adult age and sexual size dimorphism as determinants of pre-copulatory sexual cannibalism in virgin wolf spiders. Behav Ecol Sociobiol 71:10.

Gebhardt-Henrich SG, Van Noordwijk AJ (1991) Nestling growth in the great tit I. Heritability estimates under different environmental conditions. J Evol Biol 4:341362.

Gnatzy W, Otto D (1996) Digger wasp vs. cricket: application of the paralytic venom by the predator and changes in behavioural reactions of the prey after being stung. Naturwissenschaften 83:467-470.

Grafen A (1988) On the uses of data on lifetime reproductive success. Reprod Success: 454-471.

Griffiths D (1980) Foraging Costs and Relative Prey Size. Am Nat 116:743-752.

Grinsted L, Schou MF, Settepani V, Holm C, Bird TL, Bilde T (2020) Prey to predator body size ratio in the evolution of cooperative hunting-a social spider test case. Dev Genes Evol 230:173-184.

Groothuis TGG, Schwabl H (2008) Hormone-mediated maternal effects in birds: 

363:1647-1661.

Gustafsson S, Rengefors K, Hansson LA (2005) Increased consumer fitness following transfer of toxin tolerance to offspring via maternal effects. Ecology $86: 2561-$ 2567.

Hadfield JD (2010) MCMC Methods for Multi-Response Generalized Linear Mixed Models: The MCMCgImm R Package. J Stat Softw 33.

Hagstrum DW (1971) Carapace Width as a Tool for Evaluating the Rate of Development of Spiders in the Laboratory and the Field. Ann Entomol Soc Am 64:757-760.

Hansen TF (2013) Why epistasis is important for selection and adaptation. Evolution

$$
67: 3501-3511 .
$$

Hart SP, Schreiber SJ, Levine JM (2016) How variation between individuals affects species coexistence. Ecol Lett:825-838.

Heath DD, Fox CW, Heath JW (1999) Maternal Effects on Offspring Size: Variation Through Early Development of Chinook Salmon. Evolution 53:1605.

Hirvonen H, Ranta E (1996) Prey to predator size ratio influences foraging efficiency of larval Aeshna juncea dragonflies. Oecologia 106:407-415.

Inchausti P, Ginzburg LR (2009) Maternal effects mechanism of population cycling: a formidable competitor to the traditional predator-prey view. Philos Trans R Soc B Biol Sci 364:1117-1124.

Jakob EM, Marshall SD, Uetz GW (1996) Estimating fitness: a comparison of body condition indices. Oikos 77:61-67.

Jensen K, Mayntz D, Toft S, Raubenheimer D, Simpson SJ (2011) Nutrient regulation in a predator, the wolf spider Pardosa prativaga. Anim Behav 81:993-999. 
Jiang L, Morin PJ (2005) Predator diet breadth influences the relative importance of bottom-up and top-down control of prey biomass and diversity. Am Nat 165:350363.

De Jong G, Imasheva A (2000) Genetic variance in temperature dependent adult size deriving from physiological genetic variation at temperature boundaries. Genetica 110:195-207.

Jonsson T, Ebenman B (1998) Effects of predator-prey body size ratios on the stability of food chains. J Theor Biol 193:407-417.

Keightley PD, Kacser H (1987) Dominance, pleiotropy and metabolic structure. Genetics 117:319-329.

Laigle I, Aubin I, Digel C, Brose U, Boulangeat I, Gravel D (2018) Species traits as drivers of food web structure. Oikos 127:316-326.

LaMontagne JM, McCauley E (2001) Maternal effects in Daphnia: What mothers are telling their offspring and do they listen? Ecol Lett 4:64-71.

Lindholm AK, Hunt J, Brooks R (2006) Where do all the maternal effects go? Variation in offspring body size through ontogeny in the live-bearing fish Poecilia parae. Biol Lett 2:586-589.

Lynch M, Walsh B (1998) Genetics and analysis of quantitative traits. Sinauer Sunderland.

Magalhães S, Janssen A, Montserrat M, Sabelis MW (2005) Prey attack and predators defend: Counterattacking prey trigger parental care in predators. Proc R Soc B Biol Sci 272:1929-1933.

Matlock RB (2005) Impact of Prey Size on Prey Capture Success, Development Rate, and Survivorship in Perillus bioculatus (Heteroptera: Pentatomidae), a Predator of 

the Colorado Potato Beetle. Environ Entomol 34:1048-1056.

657

658

659

660

661

662

663

664

665

666

667

668

669

670

671

672

673

674

675

676

677

678

679

Maynard DS, Serván CA, Capitán JA, Allesina S (2019) Phenotypic variability promotes diversity and stability in competitive communities. Ecol Lett 22:1776-1786.

McGlothlin JW, Ketterson ED (2008) Hormone-mediated suites as adaptations and evolutionary constraints. Philos Trans R Soc B Biol Sci 363:1611-1620.

Merilä J, Kruuk LEB, Sheldon BC (2001) Natural selection on the genetical component of variance in body condition in a wild bird population. J Evol Biol 14:918-929.

Moore MP, Whiteman HH, Martin RA (2019) A mother's legacy: the strength of maternal effects in animal populations. Ecol Lett 22:1620-1628.

Moskalik B, Uetz GW (2011) Female hunger state affects mate choice of a sexually selected trait in a wolf spider. Anim Behav 81:715-722.

Mousseau TA, Fox CW (1998) Maternal effects as adaptations. Oxford University Press.

Mousseau TA, Roff DA (1987) Natural selection and the heritability of fitness components. Heredity 59:181-197.

Moya-Larano J (2002) Senescence and food limitation in a slowly ageing spider. Funct Ecol 16:734-741.

Moya-Laraño J (2011) Genetic variation, predator-prey interactions and food web structure. Philos Trans R Soc B Biol Sci 366:1425-1437.

Moya-Larano J, Barrientos JA, Orta-Ocana JM, Bach C, Wise DH (1998) Limitación por la comida en las tarántulas del Cabo de Gata (Almeria). Investig y Gestión del Medio Nat 3:73-77.

Moya-Laraño J, Macías-Ordóñez R, Blanckenhorn WU, Fernández-Montraveta C (2008) Analysing body condition: Mass, volume or density? J Anim Ecol 77:1099-1108.

Moya-Laraño J, Orta-Ocaña JM, Barrientos JA, Bach C, Wise DH (2002) Territoriality in a 
681

682

683

684

685

686

687

688

689

690

691

692

693

694

695

696

697

698

699

700

701

702

Moya-Laraño J, Verdeny-Vilalta O, Rowntree J, Melguizo-Ruiz N, Montserrat M, Laiolo P, et al. (2012) Climate Change and Eco-Evolutionary Dynamics in Food Webs. In: Advances in Ecological Research, Academic Press. Vol 47, pp 1-80.

Nakazawa T (2017) Individual interaction data are required in community ecology: a conceptual review of the predator-prey mass ratio and more. Ecol Res 32:5-12.

Nakazawa T, Ushio M, Kondoh M (2011) Scale Dependence of Predator-Prey Mass Ratio. In: Advances in Ecological Research, Academic Press. Vol 45, pp 269-302.

Nentwig W, Wissel C (1986) A comparison of prey lengths among spiders. Oecologia 68:595-600.

Otto SB, Rall BC, Brose U (2007) Allometric degree distributions facilitate food-web stability. Nature 450:1226-1229.

Parellada X (1998) Identificació i dades biològiques de tres espècies de taràntules (Araneae: Lycosidae) al Garraf. II Trobades d'estudiosos del Garraf Monogr 26: $15-25$.

Patel S, Cortez MH, Schreiber SJ (2018) Partitioning the effects of eco-evolutionary feedbacks on community stability. Am Nat 191:381-394.

Persons MH, Rypstra AL (2000) Preference for chemical cues associated with recent prey in the wolf spider Hogna helluo (Araneae: Lycosidae). Ethology 106:27-35.

Pooni HS, Jinks JL, Jayasekara NEM, Jayasekara NEM (1978) An investigation of gene action and genotype $\mathrm{x}$ environment interaction in two crosses of nicotiana rustica by triple test cross and inbred line analysis. Heredity 41:83-92.

Poore AGB, Hill NA (2006) Sources of variation in herbivore preference: Among- 

1410.

Roff DA (1997) Evolutionary Quantitative Genetics. New York Chapman \& Hall.

Rooney N, McCann K, Gellner G, Moore JC (2006) Structural asymmetry and the stability of diverse food webs. Nature 442:265-269.

De Roos AM, Persson L, McCauley E (2003) The influence of size-dependent life-history traits on the structure and dynamics of populations and communities. Ecol Lett 6:473-487.

Schneider FD, Brose U, Rall BC, Guill C (2016) Animal diversity and ecosystem functioning in dynamic food webs. Nat Commun 7:1-8.

Schreiber SJ, Bürger R, Bolnick DI (2011) The community effects of phenotypic and genetic variation within a predator population. Ecology 92:1582-1593.

Schreiber SJ, Patel S, Terhorst C (2018) Evolution as a coexistence mechanism: Does genetic architecture matter? Am Nat 191:407-420.

Sheriff MJ, Krebs CJ, Boonstra R (2010) The ghosts of predators past: population cycles and the role of maternal programming under fluctuating predation risk. Ecology 91:2983-2994.

Shultz S, Noë R, McGraw WS, Dunbar RIM (2004) A community-level evaluation of the impact of prey behavioural and ecological characteristics on predator diet composition. Proc R Soc B Biol Sci 271:725-732.

Singer MC (1986) The definition and measurement of oviposition preference in plantfeeding insects. In: Insect-plant interactions, Springer New York, pp 65-94.

Stewart FM (1971) Evolution of dimorphism in a predator-prey model. Theor Popul Biol 2:493-506. 
Sztepanacz JL, Blows MW (2015) Dominance genetic variance for traits under directional selection in Drosophila serrata. Genetics 200:371-384.

Tilman D, Isbell F, Cowles JM (2014) Biodiversity and ecosystem functioning. Annu Rev Ecol Evol Syst 45:471-493.

Tsai CH, Hsieh CH, Nakazawa T (2016) Predator-prey mass ratio revisited: does preference of relative prey body size depend on individual predator size? Funct Ecol 30:1979-1987.

Violle C, Enquist BJ, McGill BJ, Jiang L, Albert CH, Hulshof C, et al. (2012) The return of the variance: Intraspecific variability in community ecology. Trends Ecol Evol 27:244-252.

Walsh MR, Castoe T, Holmes J, Packer M, Biles K, Walsh M, et al. (2016) Local adaptation in transgenerational responses to predators. Proc R Soc B Biol Sci 283:20152271.

Wang J, Caballero A, Keightley PD, Hill WG (1998) Bottleneck effect on genetic variance: A theoretical investigation of the role of dominance. Genetics 150:435447.

Wilson AJ, Réale D (2006) Ontogeny of Additive and Maternal Genetic Effects: Lessons from Domestic Mammals. Am Nat 167:E23-E38.

Wilson AJ, Réale D, Clements MN, Morrissey MM, Postma E, Walling CA, et al. (2010) An ecologist's guide to the animal model. J Anim Ecol 79:13-26.

Wolak, M. E., \& Keller, L. F. (2014) Dominance, genetic variance and inbreeding in natural populations. In: Quantitative Genetics in the Wild, Oxford University Press. pp. 104-127.

Wolf JB, Wade MJ (2016) Evolutionary genetics of maternal effects. Evolution 70:827- 
752 Woodward G, Hildrew AG (2002) Body-size determinants of niche overlap and 753 intraguild predation within a complex food web. J Anim Ecol 71:1063-1074.

754 Woodward G, Perkins DM, Brown LE (2010) Climate change and freshwater ecosystems: Impacts across multiple levels of organization. Philos Trans R Soc B Biol Sci 365:2093-2106.

757

758

759

760

761

762

763

764

765

766

767

768

769

770

771

772

773

Woodward, G., \& Warren, P. (2009) Body size and predatory interactions in freshwaters: scaling from individuals to communities. In Body Size: The Structure and Function of Aquatic Ecosystems, Cambridge University Press. pp. 98-117.

Ye L, Chang CY, García-Comas C, Gong GC, Hsieh C hao (2013) Increasing zooplankton size diversity enhances the strength of top-down control on phytoplankton through diet niche partitioning. J Anim Ecol 82:1052-1061.

Yoshida T, Jones LE, Ellner SP, Fussmann GF, Hairston NG (2003) Rapid evolution drives ecological dynamics in a predator-prey system. Nature 424:303-306.

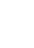

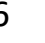

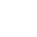

(6)

69


774 Figure 1 - Genetic $\left(r_{A}\right)$ and Maternal correlations $\left(r_{M}\right)$ among the traits measured in

775 this study. White points represent the posterior mode for the estimates measured and

776 the intervals represent Bayesian credible intervals (95\%). Significant estimates are

777 those that do not overlap zero (dashed line). BS - body size at isolation, BC - body

778 condition at isolation, PPSR - prey-to-predator size ratio.

779 
781 Table 1 -Parameter estimates (posterior mean and credible interval) for the fixed

782 effects (Age, body condition and food treatment) from analysis of standardized values

783 from the complete model $\left(V_{s}+V_{d}+V_{B}+V_{R}\right)$ for PPSR max. Post.mean - posterior mean;

$784 \mathbf{L C I}$ - lower credible interval; UCI - upper credible interval; pMCMC - p-value based on

785 MCMC sampling.

786

\begin{tabular}{ccccc}
\hline Variables & Post.mean & LCI & UCI & pMCMC \\
\hline (Intercept) & 0.036 & -0.142 & 0.22 & 0.704 \\
Age & -0.037 & -0.151 & 0.092 & 0.536 \\
Body condition & 0.139 & 0.052 & 0.216 & $<0.001$ \\
Food treatment & -0.062 & -0.223 & 0.115 & 0.475 \\
\hline
\end{tabular}




\begin{tabular}{|c|c|c|c|c|c|c|c|c|}
\hline Model & DIC & $\Delta \mathrm{DIC}$ & $V_{s}$ & $V_{d}$ & $V_{B}$ & $V_{R}$ & $h^{2}=4 V_{s} / V_{p}$ & $H^{2} \sim 4 V_{d} / V_{p}$ \\
\hline null & 1578.65 & 0 & - & - & - & - & - & - \\
\hline$V_{s}$ & 1576.98 & -1.668 & - & - & - & - & - & - \\
\hline$V_{d}$ & 1570.48 & -8.164 & - & $\begin{array}{c}0.039 \\
(0.0119-0.098)\end{array}$ & $\begin{array}{c}0.069 \\
(0.023-0.141)\end{array}$ & $\begin{array}{c}0.728 \\
(0.664-0.850)\end{array}$ & - & $\begin{array}{c}0.167 \\
(0.056-0.425)\end{array}$ \\
\hline$V_{s}+V_{d}$ & 1572.82 & -5.828 & $\begin{array}{c}0.0136 \\
(0.006-0.056)\end{array}$ & $\begin{array}{c}0.034 \\
(0.007-0.080)\end{array}$ & $\begin{array}{c}0.053 \\
(0.022-0.138)\end{array}$ & $\begin{array}{c}0.759 \\
(0.660-0.847)\end{array}$ & $\begin{array}{c}0.069 \\
(0.022-0.230)\end{array}$ & $\begin{array}{c}0.125 \\
(0.026-0.343)\end{array}$ \\
\hline
\end{tabular}




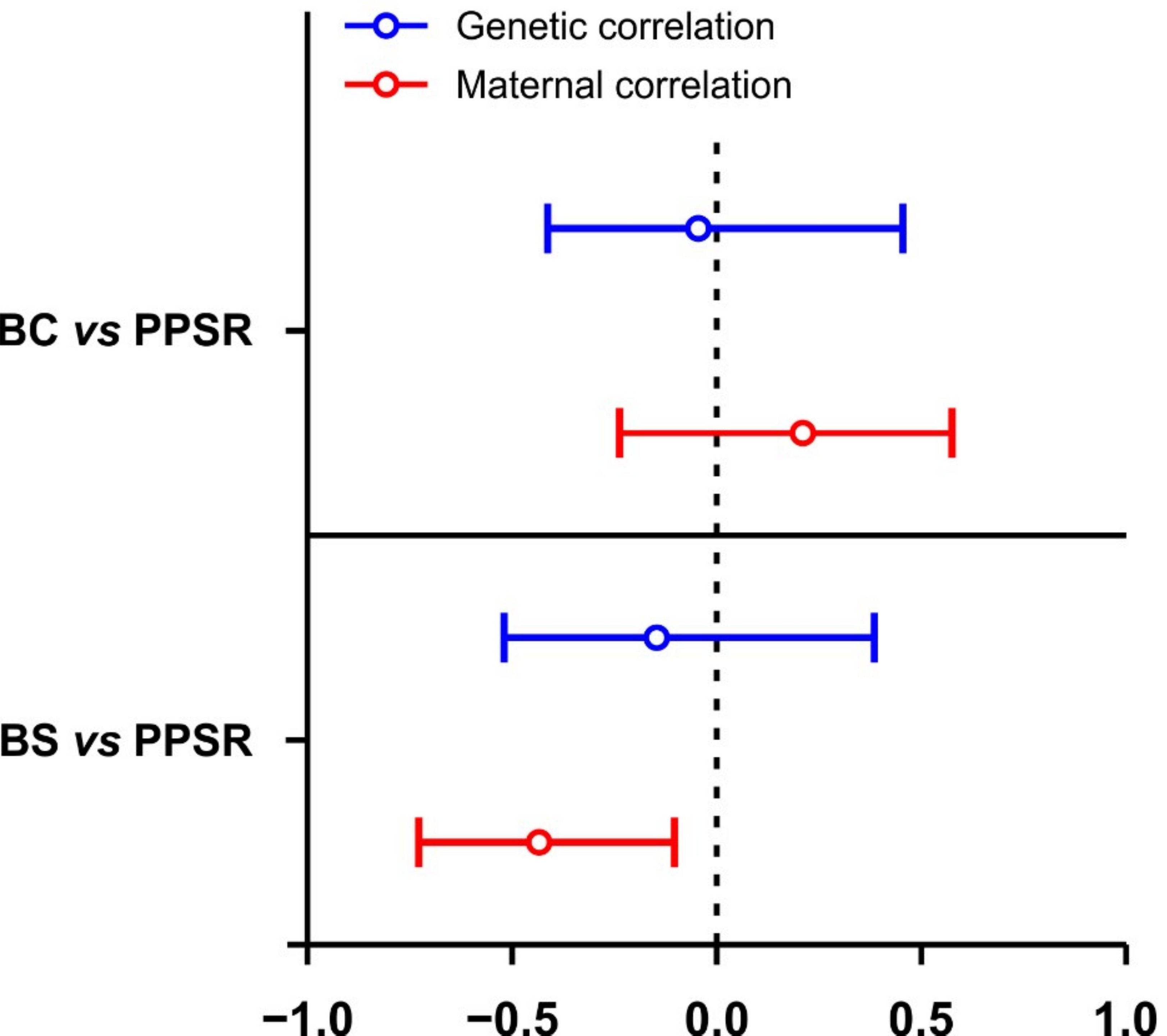

